\title{
A neuroimaging study in childhood autism
}

\author{
Mohammad S I Mullick', Wasima Rahman²,S M Abu Hena Mostafa Alim³, Hafizur Rahman Chowdhury ${ }^{4}$ \\ ${ }^{1}$ Professor of Child and Adolescent Psychiatry and Chairman, Department of Psychiatry, BSMMU. ${ }^{2}$ Medical Officer, Department of Psychiatry, \\ BSMMU. ${ }^{3}$ MD Student, Department of Psychiatry, BSMMU. ${ }^{4}$ Resident, Department of Psychiatry, BSMMU,Dhaka.
}

\begin{abstract}
:
Background: Childhood autism is now widely viewed as being of developmental neurological origin. Abnormality in neuroimaging is reported in autism. Objectives: To delineate the proportion of structural magnetic resonance imaging (MRI) and electro encephalography (EEG) abnormality among the children with Autism and to assess any association of MRI and EEG changes with co morbid mental illness. Methods: It was a cross sectional descriptive study done at a child and adolescent consultation centre, Dhaka. The study was carried out from January 2009 to December 2009.Both boys and girls were included in the study. A total of 42 children with childhood autism aged between two and 12 years participated in this study. Diagnosis of autism was based on ICD-10(DCR) criteria. Results: Abnormalities were found to be $35.7 \%$ in MRI and $42.9 \%$ in EEG. EEG abnormalities were found in the form of defuse slow waves activities, generalized faster activities, epileptogenic discharge and mixed discharge. The abnormalities in MRI was found in the form of diffuse cortical atrophic changes, focal cortical atrophy in frontal and temporal cortex with widening of major sulci, prominent ventricles, periventricular degeneration and abnormal basal ganglia. EEG changes were significantly associated with increased number of co-morbid illness (mental retardation, epilepsy and others). Conclusion: A number of abnormalities that observed in the present study indicative of relations between structural and physiological dysfunctions and childhood autism. Further exploratory and in-depth researches are certainly required in this field. Intervention of autism needs to address co morbidities for better outcome.
\end{abstract}

Key words: Autism, Neuroimaging, Co morbidity

[BSMMUJ $2013 ; 6(2): 121-126]$

\section{Introduction :}

Autism, also referred to as autism spectrum disorder (ASD), constitutes neurodevelopmental disorder characterized by impairment in communication, including language, social skills and comportment often involving rigidity of interests and repetitive, stereotypical behaviors. ${ }^{1}$ The prevalence of autism is estimated at 2-5per10, 000 with number expanding to $10-20$ per 10,000 if broader definitions are used. ${ }^{2,3}$ The male: female ratio is about $3: 1 .^{4}$ In Bangladesh, first exploratory study in 2005 on child psychiatric disorders in rural, urban and slum areas reported the prevalence of autism is $0.2 \%$ (ranged up to $0.9 \%)^{5}$. The incidence of autism appears to

Address for Correspondence: Mohammed SI Mullick Professor of child and Adolescent Psychialy and charman Department of Pschiatry, BSMMU Mobile: 01911288672 be increasing. In 2011, Manning et al. using birth certificate and Early Intervention data reported that in the Commonwealth of Massachusetts between 2001 and 2005 the incidence of ASD diagnosed by 36 months of age increased from 56 to 93 infants per 10,000. Whether this increased incidence reflects better reporting and/or diagnosis or whether other factors are involved remains to be determined. None-the-less, such an increase in incidence is alarming. ${ }^{6}$ ASD is considered by leading researchers to be a genetically determined disorder in three representative twin studies. ${ }^{7-9}$ Estimated heritability is about $90 \% .{ }^{10}$ Sibling concordance varies from about 3 to $14 \%$; linkage studies are consistent with a polygenic mode of transmission. ${ }^{11}$ Analysis of several studies revealed that there was a link between autism, seizures, signs of neurological impairment and mental retardation which provided evidence that autism is a pervasive devel- 
opmental disorder with a neurological basis. ${ }^{12}$ During typical development, the brain undergoes a highly dynamic process of dendritic branching, synaptic pruning, and myelination, which continues into adolescence and adulthood. ${ }^{13-17}$ In contrast, the brains of at least some autistic children are hypothesized to undergo accelerated brain growth before age two followed by a premature slowing of growth. ${ }^{18,19}$ Aberrant growth rates in brain regions implicated in social impairment, communication deficits and repetitive behaviors in autism, suggesting that growth rate abnormalities persist into adolescence. ${ }^{20}$ No focal defect has been demonstrated in structural MRI. Important findings, so far, include increased brain volume, structural abnormality in frontal lobe and corpus callosum in a proportion of Autistic individuals. ${ }^{21}$ From a public health perspective, ASDs are an important cause of morbidity high service utilization because of their early onset, lifelong persistence, high level of associated impairment, and absence of effective treatment for the core problems. ${ }^{22}$ Less well-investigated cause of impairment may be psychiatric co morbidities. For other psychiatric disorders, co morbidity is common, although the cause are often not well understood.$^{23-25}$ Delineating psychiatric co morbidity may identify targets for specific intervention that could reduce overall impairment and improve quality of life. . $^{26,27}$

It is evident from representative studies that neuroanatomical and neurophysiological abnormalities as well as significant co morbid mental illness exist among the children with autism. Sharing clinical experience with related professionals, we also developed the similar impressions and intended to explore these issues in Bangladesh. Therefore, this study was aimed to delineate the proportion of structural magnetic resonance imaging (MRI) and electro encephalography (EEG) abnormality among the children with Autism and to assess any possible association of MRI and EEG changes with co morbid mental illness.

\section{Methods :}

It was a cross sectional, descriptive study. The study was done at Child and Adolescent consultation centre, Dhaka. The study was carried out from January 2009 to December 2009. Both boys and girls within age ranges 2-12 years were included in the study. A selection criterion for the study was the ICD-10 DCR criteria for Childhood Autism. The study place was selected by convenient sampling technique. A total 42 sample were taken consecutively who fulfilled the inclusion criteria and consent given by the guardian. All the ethical issues have been considered in the study. A structured questionnaire designed by the researcher to collect information related to sociodemographic data of the children and guardians. Informations that included in this questionnaire were child age, sex, education status, habitat and social status. ICD-10 DCR is the $10^{\text {th }}$ revision of International Classification of Diseases by the World Health Organization which was used for diagnosis of autism and other co-morbid psychiatric disorders. ${ }^{28}$ Clinical assessment of low IQ was confirmed by applying psychometric test by using The Wechsler Intelligence Scale for Children (WISC-R) to assign Mental retardation according to ICD-10 DCR. It was developed by David Wechsler, is an individually administered intelligence test for children between the ages of 6 and 16 inclusive that can be completed without reading or writing. The WISC takes $65-80$ minutes to administer and generates an IQ score which represents a child's general cognitive ability. The current version, the WISC-IV was produced in 2003 followed the UK version in 2004. WISC has proven validity and reliability. WISC-R (1974) ${ }^{29}$ has been translated and adopted in Bangla for using this scale among Bangladeshi children. The scale is also usable in the children of 1-2 years of age. This Bangla WISC-R was used in this study. The subjects were only categorized as mentally retarded, but no other subgroups of mental retardation were considered. Information provided by the guardian and referring physicians regarding seizure disorder and diagnosis of seizure were recorded accordingly. In Bangladesh, best possible and sizable clinical neuromiaging are EEG and structural MRI that were used in this study. For each subject, 24 channeled EEG recording was performed. The electrodes were placed according to the $10 / 20$ international system. Restless or anxious patients were pre-medicated by a low dose of diazepam. The EEG assessment was performed by one experienced neurologist. The rater was blind to psychopathology of the patients. The EEG record was divided into three groups: normal EEGs, EEG with non-epileptiform abnormality of background activity, abnormal EEG with epileptiform discharges. The patients 
have also under gone MRI scanning to detect structural abnormality of brain. The statistical analysis was performed using the Statistical Package for the Social Sciences (SPSS, version 17.0). Descriptive statistics and Chi-Square test were used for the analysis of the relationship between co-morbidities with EEG and MRI findings.

\section{Results:}

Among 42 participants male and female representations were $33(78.6 \%)$ and $9(21.4 \%)$ respectively. Mean age was 6.24 years (ranges $2 \mathrm{y} 4 \mathrm{~m}$ to $12 \mathrm{y}$ ). Socioeconomic status categorizes as highl6 (38.1\%), middle $25(59.5 \%)$ and low $1(2.4 \%)$. Table $-\mathrm{I}$ revels that most of the participants were not attending to any school, only two were attending special and three in main stream school but with low academic performance. Figure-1 shows the comorbidity with Childhood autism.

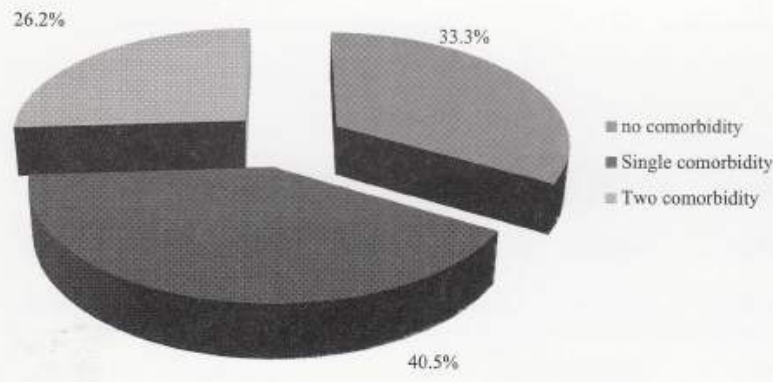

Fig 1 : Frequency of co-morbid illness

Comorbid illness was found among 28(66.7\%). Type and frequency of comorbidity is shown in Table-II. Among comorbid illness hyperkinetic disorder was most frequent $(54.8 \%)$. More than two co morbid illness present in $26.2 \%$ of cases. Electroencephalographic (EEG) findings are presented in Table-III. EEG report revealed normal activity, epilepogenic discharge and, non-epileptogenic discharge in $57.1 \%, 28.6 \%, 14.3 \%$ cases respectively. Table-IV shows the findings of MRI of brain of the cases. Abnormality in MRI findings was found in $35.7 \%$ cases. Table-V shows the relation between co morbid illness with EEG and MRI of the brain findings.EEG abnormality with co morbidity and MRI abnormality with co morbidity found in $66.7 \%$ and $73.3 \%$ cases respectively. There is an increase number of co morbidity related with EEG abnormality (Table-VI).
Table-I

Characteristics of Subjects

\begin{tabular}{llcc}
\hline Variables & & Frequency & Percent \\
\hline Age in Category & 2 -5 year & 20 & 47.6 \\
& 6-9 year & 17 & 40.5 \\
& $10-13$ year & 5 & 11.9 \\
Sex & Male & 33 & 78.6 \\
& female & 9 & 21.4 \\
Habitat & & & \\
& rural & 8 & 19 \\
Socio-economic & urban & 34 & 81 \\
status & Variables & Frequency & Percent \\
& Middle & 16 & 38.1 \\
Education & Low & 25 & 59.5 \\
& No education & 37 & 88.1 \\
& Main stream & 3 & 7.1 \\
& education & & \\
& Special education & 2 & 4.8 \\
\hline
\end{tabular}

Table-II

Types and frequency of co-morbid illness

\begin{tabular}{|c|c|c|c|c|c|c|}
\hline & \multicolumn{6}{|c|}{$\begin{array}{c}\text { Hyperkinetic } \\
\text { disorder }\end{array}$} \\
\hline & $\begin{array}{l}\text { Frequ } \\
\text { ency }\end{array}$ & Percent & $\begin{array}{l}\text { Frequ } \\
\text { ency }\end{array}$ & Percent & $\begin{array}{l}\text { Frequ } \\
\text { ency }\end{array}$ & Percent \\
\hline Present & 14 & 33.3 & 23 & 54.8 & 2 & 4.8 \\
\hline Absent & 28 & 66.7 & 19 & 45.2 & 40 & 95.2 \\
\hline Total & 42 & 100.0 & 42 & 100.0 & 42 & 100.0 \\
\hline
\end{tabular}

Table-III

Electro encephalogram (EEG) findings

\begin{tabular}{lll}
\hline & Frequency & Percent \\
\hline Normal & 24 & 57.1 \\
Epileptiform discharge & 12 & 28.6 \\
Generalized Absence & 1 & 2.4 \\
Localized epileptiform & & \\
discharge & 3 & 7.1 \\
GTCS & 8 & 19.0 \\
Non Epileptiform & 6 & 14.3 \\
discharge & & \\
Nonspecific changes & 3 & 7.1 \\
Generalized slow & 3 & 7.1 \\
activities & & \\
\end{tabular}


Table-IV

Findings of MRI of brain

\begin{tabular}{|c|c|c|c|}
\hline & & Frequency & Percent \\
\hline \multirow[t]{5}{*}{$\begin{array}{l}\text { Normal } \\
\text { Abnormal }\end{array}$} & & 15 & 35.7 \\
\hline & ganglia & 2 & 4.8 \\
\hline & Enlarged ventricle & 8 & 19.0 \\
\hline & cortical atrophy & 3 & 7.1 \\
\hline & others & 2 & 4.8 \\
\hline Total & & 42 & 100.0 \\
\hline
\end{tabular}

Table-V

Relation between co-morbid illnesses with EEG \& MRI finding

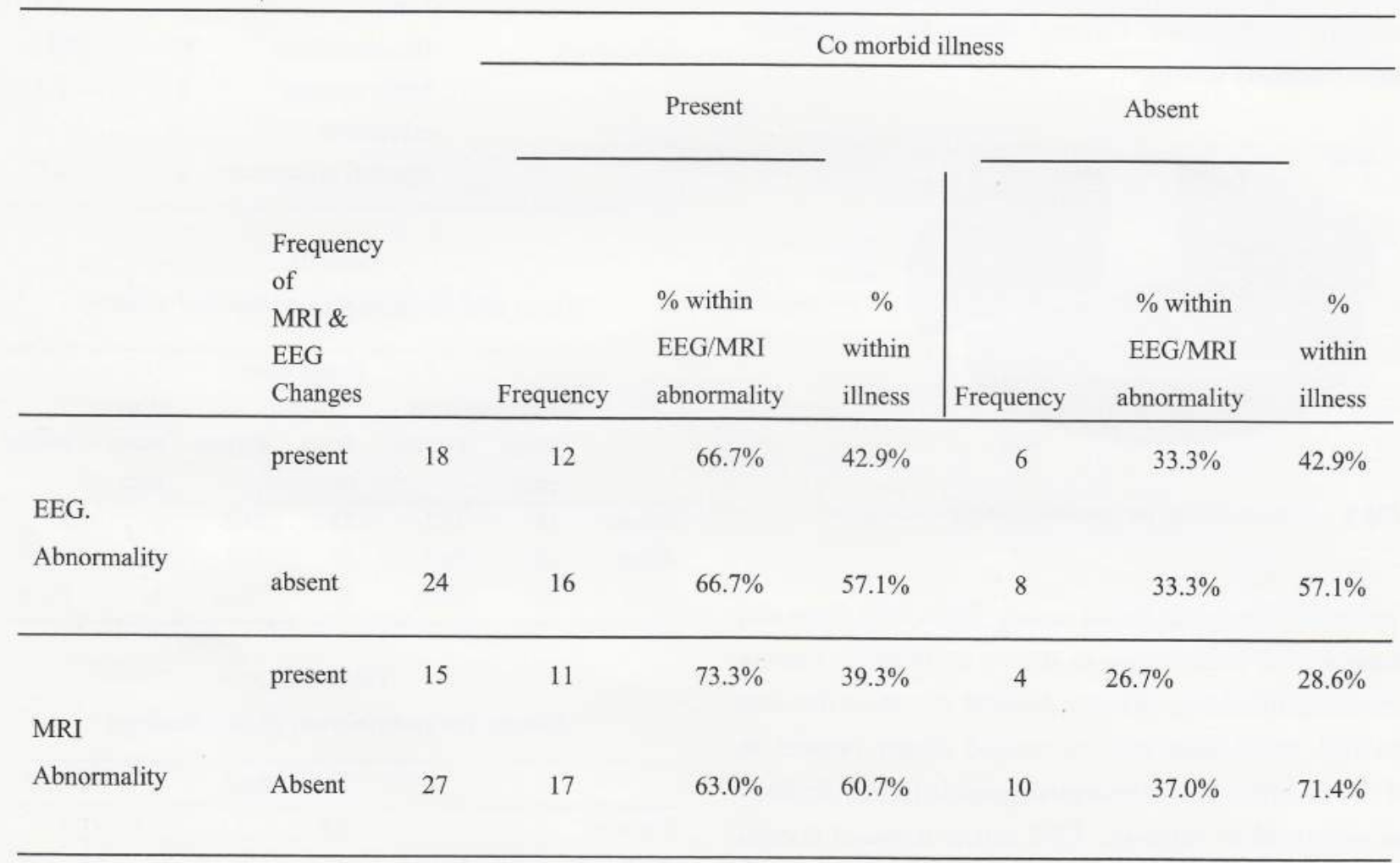

Table-VI

Relationship between number of co-morbid illness and EEG abnormality

\begin{tabular}{cccc}
\hline \multirow{2}{*}{ Number of Comorbid illness } & \multicolumn{2}{c}{ EEG.Abnormality } & \\
\cline { 2 - 3 } & present & absent & Total \\
\hline 0 & 6 & 8 & 14 \\
1 & 4 & 13 & 17 \\
2 & 8 & 3 & 11 \\
Total & 18 & 24 & 42 \\
\hline
\end{tabular}




\section{Discussion :}

This study explored the possible association of neuroimaging in autism. Though seizure disorder was present only among $4.8 \% \quad(n=2)$ of patients, EEG changes were detected among $42.9 \%$ that was considerably significant. Of the two abnormalities, one had EEG changes suggestive of GTCS while another one had nonspecific EEG changes. Among non epileptic patients, $27.5 \%$ had epileptiform discharge and $12.5 \%$ had Nonspecific abnormalities . This result differs from a study which showed $18.2 \%$ of autistic patients with co-morbid epilepsy had non epileptiform abnormality and $37.5 \%$ had epileptiform discharge; while among the patients not having epilepsy, $81.8 \%$ had non epileptiform abnormality and $62.5 \%$ had epileptiform discharge. ${ }^{30}$ However a clear inference cannot be drown as number of patients having seizure in this study was only two. EEG changes were found in $33.3 \%$ of patients without presence of any co morbidity. Above findings suggest an association between ASD and EEG changes. As this study was not a case control study, it was not possible to find out any significant change in EEG pattern from normal individual. Duffy and Als $(2012)^{31}$ found that these two groups differed significantly on the basis of variables generated from EEGbased coherence data. Classification success suggests a stable coherence loading pattern that differentiates ASDfrom Control group subjects. This might constitute an EEG coherence-based phenotype of childhood autism . Therefore; broad based case control study can reproduce the data. In another study, Kim et al. ${ }^{32}$ found majority $(69 \%)$ of patients had EEG abnormality comprising of Non Epileptogenic abnormality, Epileptogenic abnormality and combination. No patients with autism had recorded epileptic seizures, despite the high prevalence of Interictal EEG abnormalities. In this study more than one third of the patients had abnormal structural MRI findings. Changes in basal ganglia were found among $4.8 \%$ such as multiple hypodense area seen in both lentiform nuclei and head of left caudate nuclei that is dystrophic calcification and enlarged basal ganglia. Though many articles for decades showed increased brain volume. ${ }^{33,34.21}$ This study failed to replicate this findings; rather we found generalized mild cortical atrophy, focal area- right high anterior frontal cortex, bilateral temporal cortical atrophy. More extensive neuroimaging study on large sample comparing with control group could help in drawing conclusion. Other changes included prominent cistern magna with smaller posterior vermis of the cerebellum (lobule VI - VII) which is consistent with a study done by Kaufmann et al. ${ }^{35}$ There is a similarity between this study and study done by Courehence where the author found enlargement of central nervous system fluid space i.e. enlarged lateral ventricle, enlarged frontotemparo- parietal cistern, prominent cistern magna etc. ${ }^{36}$

Present study revealed that co morbidity with autism is high $(67 \%)$. Of the psychiatric co-morbidities hyperkinetic disorder and mental retardation were found $55 \%$ and $33 \%$ respectively. This finding simulates with the report of the first clinical study of Autism in a tertiary hospital in Dhaka. This study found $64 \%$ and $48 \%$ co-morbidity of hyperactivity and mental retardation respectively.37 of the co-occurring medical condition, seizure disorder was found $5 \%$ in our study. Co occurring seizure disorder was found $20 \%$ in report of the clinical study of Autism in a tertiary hospital in Dhaka. ${ }^{37}$ Possible explanation of lower proportion of seizure disorder in our study might be due to the difference in pattern of attendance of the two study centres. In private consultation centre, the autistic patents with seizure disorders usually go for pediatric or neurologic consultation. In tertiary hospital setup, these patient populations attend more in psychiatry outpatient department. Further exploration is required to confirm these findings. Though neuroimaging abnormalities with or without co-morbidities are not significant, overall these abnormalities are higher in autistic patients with co-morbidities. The co-morbidities might be associated with increased structural and/or/functional brain abnormalities either as the manifestation of multiple or common etiological pathways. In-depth and extensive studies are required in this area that will certainly contribute in exploring aetiology of autism.

\section{Conclusion :}

The present study indicates that structural and physiological dysfunctions are related to childhood autism. Further explorations are needed to understand the aetiological aspects of Autism and its clinical implications. High number of co-morbidities that found in this study 
number of co-morbidities that found in this study indicates biological or genetic aetiology of childhood autism. Targeting the evaluation of comorbid mental illness and intention for early intervention will improve the quality of life of children with autism.

\section{References:}

1. American Psychiatric Association: In Diagnostic and Statistical Manual of Mental Disorders Fourth Edition Text Revision (DSMIV-TR). American Psychiatric Association. Washington, DC: American Psychiatric Publishing, Inc.; 2000: 4

2. Wing L, Gould J. Severe impairment of social interaction and associated abnormalities in children: epidemiology and classification. J Autism Dev Dis 1979; 9: 11-29.

3. Bryson SE, Clark BS, Smith TM. First report of a Canadian epidemiological study of Autistic syndromes. J Child Psychol Psychiatry 1988; 29:433-45.

4. Lord C, Schopler E, Revick D. Sex Differences in autism. J Autism Dev Dis 1982; 12:317-30.

5. Mullick M, Goodman R. The prevalence of psychiatric disorders among 5-10 year olds in rural, urban and slum areas in Bangladesh. Soc Psychiatry Psychiatr Epidemiol 2005; 40:663-71.

6. Manning SE, Davin CA, Barfield WD, Kotelchuck M, Clements K, Diop H, et al. Early diagnoses of autism spectrum disorders in Massachusetts birth cohorts 2001-2005. Pediatrics 2011; 127:1043-51.

7. Bailey A, Le Couteur A, Gottesman I, Bolton P, Simonoff E, Yuzada E, Rutter M. Autism as a strongly genetic disorder: evidence from a British twin study. Psychol Med 1995; 52:63-77.

8. Folstein S, Rutter M. Infantile autism: a genetic study of 21 twin pairs. J Child Psychol Psychiatry 1977; 18: 297-321.

9. Steffenburg S, Gillberg C, Steffenburg U. Psychiatric disorders in children and adolescents with mental retardation and active epilepsy. Arch Neurol 1996; 53:904-92.

10. Hallmayer J, Cleveland S, Torres A, Phillips J, Cohen B, Torigue T, et al. Genetic heritability and shared environmental factors among twin pairs with autism. Arch Gen Psychiatry 2011; 68:1095-102.

11. Risch N, Spiker D, Lotspeich L, Nouri N, Hinds D, Hallmayer J, et al. A genomic screen of autism: evidence for a multilocus etiology. Am J Hum Genet 1999; 65:493-507.

12. Minishew N. Indices of neural function in autism: clinical and biological implications. Paediatrics 1991; 31:774-50.

13. Giedd JN, Blumenthal J, Jeffries NO, Castellanos FX, Liu H, Zijdenbos A, et al. Brain development during childhood and adolescence: A longitudinal MRI study. Nat Neurosci 1999; 2: 861-83.

14. Gogtay N, Giedd JN, Lusk L, Hayashi KM, Greenstein D, Vaituzis $\mathrm{AC}$, et al. Dynamic mapping of human cortical development during childhood through early adulthood. Proc Natl Acad Sci USA 2004; 101:8174-79.

15. Knickmeyer RC, Gouttard S, Kang C, Evans D, Wilber K, Smith JK et.al. A structural MRI study of human brain development from birth to 2 years. J Neurosci $2008 ; 28: 12176-82$.

16. Sowell ER, Thompson PM, Holmes CJ, Batth R, Jernigan TL, Toga AW : Localizing age-related changes in brain structure between childhood and adolescence using statistical parametric mapping. Neuroimage 1999; 9:587-97.
17. Sowell ER, Thompson PM, Leonard CM, Welcome SE, Kan E, Toga AW: Longitudinal mapping of cortical thickness and brain growth in normal children. J Neurosci 2004; 24:8223-31.

18. Courchesne E. Brain development in autism. Early overgrowth followed by premature arrest of growth. Ment Retard Dev Desabil Res Rev 2004; 10:106-111.

19. Courchesne E, Redcay E,Kennedy DP. The autistic brain Birth through adulthood. Curr Openion Neurol 2004; 17:489-96.

20. Xua Hua, Paul M Thompson, Alex D. Leow, Sarah K,Madsen et al. Brain growth rate abnormalities visualized in adolescent with autism. Hum Brain Mapp 2011; 34:425-36.

21. Deb S, Thompson B. Neuroimaging in autism. Br J Psychiatry 1998; 173:299-02.

22. Jarbrink K,Fombonne E, Knapp M. Measuring the parental service and cost impacts of the children with autistic spectrum disorder: a pilot study. J Autism Dev Disord 2003; 33:395-402.

23. Costello EJ,Mustillo S, Erkanli A, Keeler G. A prevalence and development of psychiatric disorders in childhood and adolescence. Arch Gen Psychiatry 2003; 60:837-44

24. Ford T, Goodman R, Meltzer H. The British Child and Adolescent Mental Health Survey 1999: the prevalence of DSM-IV disorders. J Am Acad Child Adolesc Psychiatry 2003:42: 1203-11.

25. Simonoff E, Pickles A, Meyer JM, et al. The Virginia Twin Study of Adolescent Behavioral Development: influence of age, gender and impairment on rates of disorder. Arc Gen Psychiatry 1997; 54:801-8.

26. Caron C, Rutter M. Co morbidity in psychopathology; concepts, issues and research strategies. J Child Psychol Psychiatry1991; 32:1063-81

27. Neale MC, Kendler KS. Models for comorbidity of multifactorial disorders. Am J Hum Gent 1995; 57:935-53.

28. World Health Organization (1993). The ICD-10 Classification of mental and behavioural disorders: diagnostic criteria for research. World Health Organization, Geneva.

29. Wechsler, D. (1974). Manual for the Wechsler Intelligence Scale for Children-Revised. New York: Psychological Corporation.

30. M. Hrdlicka , V. Komarek. Not EEG abnormalities but epilepsy is associated with autistic regression and mental functioning in childhood autism. Euro Child Adolesc Psychiatry 2004 : 13:209-13.

31. Frank H Duffy, Heideleise Als. A stable pattern of EEG spectral coherence distinguishes children with autism from neurotypical controls- a large case control study. BMC Medicine 2012.Available from http://www.biomedcentral.com/1741-7015/10/64

32. Kim HL, Donnelly JH, Tournay AE, Book TM, Filipek P. Absence of seizures despite high prevalence of epileptiform EEG abnormalities in children with autism monitored in a tertiary care center. Epilepsia 2006; 47:394-98,

33. Brambilla P, Hardan A, di Nemi SU, et al . Brain anatomy and development in autism: review of structural MRI Studies. Brain Res Bull 2003; 61: 557-693.

34. Hardan A, Minshew N,Mallikarjuhn M, Keshaven M. Brain volume in autism. J Child-Neurol 2001; 16: 412-4.

35. Kaufmann WE, Cooper KL, Mostofsky SH,Capone GT,Kates WR, Newschaffer CJ et al. Specificity of cerebellar vermian abnormalities in autism : a quantitative MRI study. J Child Neurol 2003; 18:463-70.

36. Courehesne E. Neuroanatomic imaging in autism. Paediatrics 1991; 31:781-99.

37. Mullick MSI. Clinical profile of autism-a study of 56 cases. Bangladesh J Child Health 2000:24:6-14. 